\title{
Proceeding
}

Supplementary Issue: Winter Conferences of Sports Science. Costa Blanca Sports Science Events, 22-23 March 2021. Alicante, Spain.

\section{Dynamics of the morphofunctional state of students with the expansion of fitness means in physical education classes}

\author{
TATIANA SHUTOVA, TATIANA VYSOTSKAYA $\triangle$, RAZAMBEK PIHAEV, JULIA POLSHIKOVA \\ Department of Physical Education, Plekhanov Russian University of Economics, Russian Federation
}

\begin{abstract}
Purpose: to study the dynamics of the morphofunctional state of students during expanding fitness means in physical education classes. Materials and methods: students at the University of Economics $(n=820$, age $18.0 \pm 0.76$ years) took part in the study. The experiment was lasting for 36 months. With students of group $\mathrm{N} 1(\mathrm{n}=386)$, traditional classes were conducted in accordance with the current physical education program. Development of physical education in group N2 $(n=434)$ was carried out by increasing the means of fitness and daily monitoring of physical activity with modern devices. Functional diagnostics was carried out on the hardware-diagnostic complex «Esteck System Complex». «Omega-M» hardware and software complex was used for studying biological rhythms. The evaluation of working capacity of the cardiovascular system was determined using the Ruffier test. Results: in group N2, authentic differences were determined in the adequacy of the regulation processes, the integral indicator of the sports shape, the level of physical activity (the number of steps per day). In group N1, authentic differences were determined only in the level of physical activity. At the same time, there was no significant improvement in the morphofunctional state in the groups. Conclusions: thanks to the expansion of fitness means, the provision of an individual-typological medical record and the stimulation of physical activity, it was managed to achieve a positive dynamic of the morphofunctional state of students of group N2.
\end{abstract}

Keywords: Physical activity; Fitness; Physical exercises; Functional diagnostics.

Cite this article as:

Shutova, T., Vysotskaya, T., Pihaev, R., \& Polshikova, J. (2021). Dynamics of the morphofunctional state of students with the expansion of fitness means in physical education classes. Journal of Human Sport and Exercise, 16(3proc), S1006-S1015. https://doi.org/10.14198/jhse.2021.16.Proc3.17

Corresponding author. Department of Physical Education, Plekhanov Russian University of Economics, Russian Federation. https://orcid.org/0000-0002-2430-0345

E-mail: golubnichaya2010@yandex.ru

Abstract submitted to: Winter Conferences of Sports Science. Costa Blanca Sports Science Events, 22-23 March 2021. Alicante, Spain.

JOURNAL OF HUMAN SPORT \& EXERCISE ISSN 1988-5202.

(c) Faculty of Education. University of Alicante.

doi:10.14198/jhse.2021.16.Proc3.17

S1006 | 2021| Proc3 | VOLUME 16

(c) 2021 University of Alicante 


\section{INTRODUCTION}

An objective evaluation and interpretation of the criteria for the functional state of the organism of students are a prerequisite for a scientific approach to learning. Such an evaluation helps in the organization of the studying process in physical education (José Enrique et al., 2021; Katewongsa et al., 2021). It provides objective information for health management and planning of physical activity of students. Scientific research in the field of the functional state of the organism can be as means of prophylaxis, foresight, and prevention of deterioration in health (Joensuu et al., 2021; Zakariya et al., 2021; Junger et al., 2020). Hardware diagnostic techniques are an integral part of planning physical education lessons. They integrate objective information, testify to the effectiveness of the means of physical education and sports used (Shi, 2021; Andryushchenko et al., 2018; Osipov et al., 2018).

Due to a decrease in the state of health and physical fitness of students, the evaluation and control of the morphofunctional state in physical education lessons are becoming increasingly important (Fühner et al., 2021; Shutova et al., 2020; Shutova et al., 2018). Only 37.3\% of the surveyed students of economic specialties have a high level of recovery of the cardiovascular system after standard physical activity (for example, 30 squats). Average level - $34 \%$ of students, satisfactory - $28.7 \%$. The analysis of medical certificates showed that vegetative-vascular dystonia is observed in $12.5-15 \%$ of the surveyed students. Diseases of the gastrointestinal tract are observed in $10.4-15.0 \%$. Posture disorders were found in 15.6 31\% (Shutova et al., 2019; Antonova et al., 2019).

In a study by Pogodina et al. (2014) it was noted that $46 \%$ of college-age girls have a predominantly low functional level of health, and $45 \%$ have a level below average. Among boys, $15 \%$ have a low level of functional state, and $63 \%$ have a lower than average level. Average functional level of health: $9 \%$ for girls and $22 \%$ for boys. In turn, the trained students showed a predominance of a higher than average functional level: $97 \%$ for girls and $94 \%$ for boys. When testing the level of physical readiness of untrained students, the prevalence of a low level of aerobic endurance in the Cooper test was revealed.

Fitness-based technologies, as noted by Professor Saikina (2012), are relevant today in physical education classes. As well as ways to increase the level of physical fitness, focused on the personality-centred, complex nature of the impact on the organism of students (Hou et al., 2021; Kurmaeva, 2013; Shutova \& Andryushchenko, 2017; Shirokova, 2020; Shirokova et al., 2019).

The primary goal of fitness is to improve health, increase vitality, increase general and special working capacity, development of physical qualities, forming posture and correction of build defects, prophylaxis of pathological conditions, development aesthetic skills, acquirement of vital energy, vivacity, positive mood, counteract stress (Edholm et al., 2021; Melero-Cañas et al., 2021).

Purpose: to study the dynamics of the morphofunctional state of students during expanding fitness means in physical education lessons.

\section{MATERIALS AND METHODS}

\section{Participants}

Students at the university of economics took part in the study ( $n=820$, age $18.0 \pm 0.76$ years). Students were divided into groups: control (N1, $n=386)$ and experimental $(N 2, n=434)$. 


\section{Organization of research}

The experiment took place from 2017 to 2019 on the basis of the Plekhanov Russian University of Economics (Russia, Moscow). Traditional classes were conducted with students of group N1 in accordance with the current physical education program. Classes included general physical training, athletic gymnastics, swimming, athletics, martial arts. Improvement of physical education in group N2 was carried out by increasing the means of fitness: aqua fitness, athletic gymnastics, aerobics, Pilates, elements of CrossFit. Also, students of group N2 were recommended daily monitoring of motor activity with modern devices (Finkelstein et al., 2016; Gowin et al., 2015; Jakicic et al., 2016).

Functional diagnostics was conducted using the Stock System Complex (Multiscan PRO) hardware diagnostic complex (Klochkov et al., 2016). The hardware complex allows monitoring the following indicators: heart rate variability (norm 70-100 points); hemodynamics and blood pressure (norm 70-100 points); general integral evaluation of the functional state. Also study the fat and muscle components of the body, biological age, stress index, cardiac output. Analyse the rigidity index of large vessels, the level of blood oxygen saturation. The results were displayed in 3D functional visualization: the state of the vertebral column, excessive presence of the fatty component of the body, integral evaluation of the cardiovascular system (Shutova, 2017).

«Omega-M» hardware and software complex is used to study biological rhythms. Complex analysis includes four modes: variation analysis of heart rhythms -evaluation of vegetative regulation indicators. Variation analysis includes a rhythmogram, a spectrogram. For diagnostics, the wave structure of the ECG signal is used; mapping of biorhythms of the brain - evaluation of the psychophysical state. The final mark in the "green zone» is characterized by excellent physical condition, the indicator of physical-fitness- 5 points. Satisfactory physical condition relates to the "yellow zone», and physical-fitness - 3 points. The «red zone» is characterized as poor physical condition, exhaustion, overexertion, and physical-fitness is rated at 1 point (Stepanov, 2009). The advantages of diagnostics include the fact that it is possible to simultaneously test 5 8 students.

Smart watches ONETRAK, mobile application Health, fitness bracelets and other devices were used to estimate the level of physical activity of students (number of steps per day, energy consumption, heart rate, calories burned during the day, sleep characteristics).

Evaluation of the efficiency of the cardiovascular system was determined using the Ruffier test (conv. Units). Ruffier index is less than 3 conv. units - good working capacity of the heart muscle during physical exertion, 3 - 6 conv. units - average, 7 - 9 conv. units - satisfactory, 10 - 14 conv. units - bad (average heart failure), 15 conv. units and higher - severe heart failure.

The level of regulation of the cardiovascular system was determined by the formula: where HR is the heart rate (beats / $\mathrm{min}$.), SBP is the systolic blood pressure $(\mathrm{mm} \mathrm{Hg})$. The indicators for evaluating the data are as follows: up to 74 conv. units - high level of regulation; 75-80 conv. units - above the average level of regulation of the cardiovascular system; 81-90 conv. units -average; 91-100 conv. units - below the average; 101 conv. units and higher - a low value of the regulation of the cardiovascular system.

\section{Statistical analysis}

Statistical processing of the data was carried out on generally accepted methods of variation statistics with the calculation of average arithmetic, average standard deviation and verification of the results of the study on the reliability of differences at a five percent level of significance. The Student's t-criteria was used to 
evaluate the significance of the differences. Mathematical processing was carried out using the MS Excel 2016.

\section{RESULTS}

The results of the morphofunctional state in boys are higher than in girls (Table 1). The standard deviation of the results is higher at the beginning of the experiment and slightly decreases towards the end. In group N2, in almost all the studied indicators, achieving positive dynamics of results was managed. At the same time, there was no significant improvement in the morphofunctional state in all groups. In group N2, significant differences were determined in the adequacy of the regulation processes, the integral indicator of the sports form, the level of physical activity (the number of steps per day). In group N1, significant differences were determined only in the level of physical activity. The research has showed that lessons alone are not enough to improve morphofunctional state of students. At the same time, $20 \%$ of girls and $62 \%$ of boys go in for sports on their own, which is probably why the results of boys are higher than those of girls. A low level of vital capacity of the lungs in girls was also revealed. So, in N2 the dynamics are from 2215 to $2570 \mathrm{ml}$, in N1 from 2180 to $2209 \mathrm{ml}$. In N2, increase of the vital capacity indices of the lungs was managed, however, the differences in the results are not significant. The results of young men are at the lower limit of the norm of the vital capacity of the lungs and do not significantly improve during the three years of the experiment (Table 1).

Table 1. Dynamics of the morphofunctional state of students.

\begin{tabular}{|c|c|c|c|c|c|}
\hline \multirow{2}{*}{ Indicators } & \multirow{2}{*}{ Groups } & \multicolumn{2}{|c|}{$2017(X \pm \sigma)$} & \multicolumn{2}{|c|}{$2019(\mathrm{X} \pm \sigma)$} \\
\hline & & Girls & Boys & Girls & Boys \\
\hline \multirow{2}{*}{$\begin{array}{l}\text { Body mass index } \\
\text { (conv. units) }\end{array}$} & $\mathrm{N} 2$ & $20.4 \pm 2.0$ & $22.6 \pm 2.4$ & $19.5 \pm 3.4$ & $21.1 \pm 4.1$ \\
\hline & $\mathrm{N} 1$ & $21.3 \pm 2.8$ & $20.2 \pm 3.1$ & $20.8 \pm 2.9$ & $20.6 \pm 4.4$ \\
\hline \multirow{2}{*}{ Fat mass (\%) } & N2 & $22.5 \pm 2.8$ & $20.7 \pm 5.3$ & $23.1 \pm 3.8$ & $19.8 \pm 4.3$ \\
\hline & $\mathrm{N} 1$ & $20.2 \pm 4.1$ & $18.3 \pm 2.7$ & $22.1 \pm 3.5$ & $21.8 \pm 3.6$ \\
\hline \multirow{2}{*}{$\begin{array}{l}\text { Stiffness index of } \\
\text { large vessels }(\mathrm{m} / \mathrm{s})\end{array}$} & N2 & $6.1 \pm 0.3$ & $6.3 \pm 0.5$ & $6.2 \pm 0.2$ & $6.3 \pm 0.4$ \\
\hline & $\mathrm{N} 1$ & $6.3 \pm 0.2$ & $6.2 \pm 0.3$ & $6.4 \pm 0.3$ & $6.1 \pm 0.6$ \\
\hline \multirow{2}{*}{$\begin{array}{l}\text { Reflectance index } \\
(\%) \text {, indicator of small } \\
\text { and medium muscle } \\
\text { arteries }\end{array}$} & $\mathrm{N} 2$ & $31.8 \pm 3.9$ & $30.3 \pm 2.8$ & $33.5 \pm 4.2$ & $30.9 \pm 3.1$ \\
\hline & N1 & $32.6 \pm 4.3$ & $30.8 \pm 3.8$ & $31.5 \pm 3.7$ & $32.3 \pm 4.2$ \\
\hline \multirow{2}{*}{$\begin{array}{l}\text { Peripheral vascular } \\
\text { resistance (Pa*s / } \\
\text { m3) }\end{array}$} & N2 & $1406 \pm 162$ & $1231.6 \pm 198$ & $1356 \pm 174$ & $1340 \pm 201$ \\
\hline & $\mathrm{N} 1$ & $1389 \pm 182$ & $1278 \pm 203$ & $1290 \pm 156$ & $1249 \pm 192.1$ \\
\hline \multirow{2}{*}{$\begin{array}{l}\text { Cardiac output (I / } \\
\text { min) }\end{array}$} & $\mathrm{N} 2$ & $5.0 \pm 0.6$ & $5.6 \pm 0.8$ & $5.3 \pm 0.8$ & $5.8 \pm 0.5$ \\
\hline & $\mathrm{N} 1$ & $5.6 \pm 0.6$ & $5.3 \pm 0.9$ & $5.4 \pm 0.6$ & $5.5 \pm 0.6$ \\
\hline \multirow{2}{*}{ Heart rate (bpm) } & N2 & $82.5 \pm 15.3$ & $81.6 \pm 19.1$ & $83.1 \pm 10.0$ & $77.1 \pm 9.2$ \\
\hline & $\mathrm{N} 1$ & $80.7 \pm 17.1$ & $80.7 \pm 16.4$ & $81.3 \pm 18.2$ & $81.6 \pm 12.6$ \\
\hline \multirow{2}{*}{$\begin{array}{l}\text { Blood pressure (mm } \\
\mathrm{Hg})\end{array}$} & $\mathrm{N} 2$ & $76 / 129$ & $82 / 124$ & $79,1 / 124,5$ & $82 / 125$ \\
\hline & $\mathrm{N} 1$ & $80 / 131$ & $79 / 125$ & $81,3 / 128$ & $80,1 / 124$ \\
\hline \multirow{3}{*}{$\begin{array}{l}\text { Autonomous vascular } \\
\text { tone (R-R intervals) } \\
\text { (conv. units) }\end{array}$} & N2 & $45.6 \pm 4.3$ & $47.2 \pm 4.9$ & $43.1 \pm 3.9$ & $45.2 \pm 5.1$ \\
\hline & $\mathrm{N} 1$ & $46.7 \pm 3.8$ & $45.7 \pm 4.4$ & $44.2 \pm 4.1$ & $47.6 \pm 3.4$ \\
\hline & $\mathrm{N} 2$ & $1.2 \pm 0.2$ & $1.1 \pm 0.2$ & $1.09 \pm 0.4$ & $1.1 \pm 0.3$ \\
\hline
\end{tabular}




\begin{tabular}{|c|c|c|c|c|c|}
\hline $\begin{array}{l}\text { Frequency indicator } \\
\text { of ANS activity (conv. } \\
\text { units), 0.8-1.7 - norm }\end{array}$ & N1 & $1.3 \pm 0.3$ & $0.9 \pm 0.4$ & $1.2 \pm 0.4$ & $1.1 \pm 0.4$ \\
\hline \multirow{2}{*}{$\begin{array}{l}\text { Oxygen saturation } \\
\text { level (\%), } 96-99 \% \text { - } \\
\text { normal }\end{array}$} & N2 & $96.7 \pm 0.9$ & $96.2 \pm 1.6$ & $96.9 \pm 1.4$ & $97.2 \pm 0.8$ \\
\hline & N1 & $96.0 \pm 0.7$ & $97.3 \pm 1.0$ & $96.1 \pm 0.8$ & $97.0 \pm 0.4$ \\
\hline \multirow{2}{*}{$\begin{array}{l}\text { Integral assessment } \\
\text { of the functional state } \\
\text { (score) }\end{array}$} & $\mathrm{N} 2$ & $86.5 \pm 7.8$ & $90.1 \pm 6.9$ & $92.3 \pm 5.4$ & $93.8 \pm 4.1$ \\
\hline & $\mathrm{N} 1$ & $87.0 \pm 7.0$ & $89.5 \pm 10.1$ & $89.2 \pm 5.0$ & $89.1 \pm 6.2$ \\
\hline \multirow{2}{*}{ Muscle mass (\%) } & N2 & $39.7 \pm 3.1$ & $45.5 \pm 12.8$ & $42.9 \pm 4.3$ & $51.7 \pm 6.4$ \\
\hline & $\mathrm{N} 1$ & $40.2 \pm 6.5$ & $46.2 \pm 9.5$ & $41.1 \pm 4.7$ & $48.3 \pm 7.3$ \\
\hline \multirow{2}{*}{$\begin{array}{l}\text { Lung vital capacity } \\
\text { (ml) }\end{array}$} & $\mathrm{N} 2$ & $2215 \pm 240.8$ & $3905 \pm 510$ & $2570 \pm 358$ & $4110 \pm 380$ \\
\hline & N1 & $2180 \pm 268$ & $3800 \pm 403$ & $2209 \pm 300$ & $3907 \pm 440$ \\
\hline \multirow{2}{*}{$\begin{array}{l}\text { Ruffier index (conv. } \\
\text { units) }\end{array}$} & N2 & $12.4 \pm 2.7$ & $12.6 \pm 3.6$ & $11.3 \pm 3.1$ & $10.2 \pm 1.9$ \\
\hline & N1 & $12.6 \pm 3.4$ & $11.8 \pm 4.5$ & $11.0 \pm 2.9$ & $10.8 \pm 2.9$ \\
\hline \multirow{2}{*}{$\begin{array}{l}\text { Number of steps per } \\
\text { day (number) }\end{array}$} & $\mathrm{N} 2$ & \multicolumn{2}{|c|}{5250} & \multicolumn{2}{|c|}{$8062^{*}$} \\
\hline & N1 & \multicolumn{2}{|c|}{6030} & \multicolumn{2}{|c|}{$7303^{*}$} \\
\hline \multirow{2}{*}{ Biological age (years) } & $\mathrm{N} 2$ & 22.5 & 19.1 & 21.9 & 20.0 \\
\hline & $\mathrm{N} 1$ & 22.1 & 19.0 & 22.8 & 19.6 \\
\hline \multirow{2}{*}{$\begin{array}{l}\text { Adequacy of } \\
\text { regulation processes } \\
\text { (conv. Units), the } \\
\text { norm is } 15-50 \text { conv. } \\
\text { units }\end{array}$} & $\mathrm{N} 2$ & $44.2 \pm 5.1$ & $42.7 \pm 6.6$ & $38.6 \pm 5.6^{*}$ & $30.6 \pm 3.6^{*}$ \\
\hline & N1 & $44.8 \pm 6.1$ & $40.8 \pm 5.9$ & $40.7 \pm 4.7$ & $38.1 \pm 3.9$ \\
\hline \multirow{2}{*}{$\begin{array}{l}\text { Athletic form (\%), } \\
\text { maximum 100\% }\end{array}$} & N2 & 33 & 62 & $48^{*}$ & $73^{*}$ \\
\hline & N1 & 32.9 & 65 & $40.0^{*}$ & 71.0 \\
\hline \multirow{2}{*}{$\begin{array}{l}\text { The level of } \\
\text { regulation of the } \\
\text { cardiovascular } \\
\text { system }\end{array}$} & $\mathrm{N} 2$ & $101.1 \pm 13.2$ & $94.6 \pm 10.0$ & $92.3 \pm 11.8$ & $90.0 \pm 7.3$ \\
\hline & N1 & $98.4 \pm 14.1$ & $95.1 \pm 11.4$ & $94.5 \pm 13.0$ & $93.7 \pm 8.2$ \\
\hline
\end{tabular}

Note: $\bar{X}$ - arithmetic mean, $\sigma$ - standard deviation, * - reliability of results differences.

The indicators of sports form according to the "Omega-M» method among girls changed in the group N2 from $33 \%$ to $48 \%$, in the group $\mathrm{N} 1$ from $32.9 \%$ to $40 \%$ (with the maximum value of the sports form - $100 \%$ ). In the group of young men, athletic form at the beginning of the study in N2 was $62 \%$, at the end of the experiment $73 \%$. In group $\mathrm{N} 1-65 \%$ at the beginning and $70 \%$ at the end of the study.

The reflection index in the experimental groups is practically the same, both at the beginning and at the end of the study. In the study, the girls showed a slight increase in peripheral vascular resistance both in N2 (1406 $\mathrm{Pa} \mathrm{s} / \mathrm{m} 3$ ) and in $\mathrm{N} 1$ (1389 Pa s/m3). Autonomous tone (RR-intervals of sinus origin (norm $41-50$ conventional units)) of vessels is normal in the examined students. Cardiac output in the groups is within the normal range (4.3-6.1 l/min), the results practically did not change and do not have significant differences in N2 and N1. The frequency indicator of the activity of the involuntary nervous system in the experimental groups practically does not differ, no significant differences in the results were revealed. 
Ruffier index (cardiac muscle working capacity during exercise) in group N2 among young men changed from 12.6 to 10.2 conv. units, the differences are not significant. In N1, boys have from 11.8 to 10.8 conv. units. Intergroup and intragroup differences are not significant. At the same time, the exercises according to the experimental program based on fitness made it possible in N2 to achieve a better result in terms of the cardiac muscle working capacity during physical activity, as compared with the group N1. In group N2, girls have Ruffier index from 12.4 to 11.3 conv. units, in N1 from 12.6 to 11.0 conv. units Differences in results are not significant.

At the beginning of the study, girls in group N2 had a low level of regulation - 101.1 conv. units, in N1 the result is slightly higher and amounts to 98.4 conv. units (level below average). At the end of the experiment, girls N2 exceed girls N1, while the differences are insignificant. The girls did not have a high level of regulation of the cardiovascular system. The boys also showed a level below the average at the beginning of the study. Indicators at the end of the study are slightly higher in N2 than in N1.

Table 2. Personal card of the morphofunctional state of a young man in the experimental group.

\begin{tabular}{|c|c|c|}
\hline Indicators & March 2017 & October 2019 \\
\hline Height (cm) & 188 & 188.5 \\
\hline Body weight $(\mathrm{kg})$ & 80 & 87 \\
\hline Fat mass (\%), «Estek System Complex» & 19.1 & 22.4 \\
\hline $\begin{array}{l}\text { Integral assessment of the functional state (score) max } 100 \\
\text { scores «Estek System Complex» }\end{array}$ & 93.4 & 89.1 \\
\hline Lung vital capacity (ml) & 3460 & 3800 \\
\hline Heart rate $(\mathrm{bpm})$ & 75.4 & 76.0 \\
\hline Blood pressure $(\mathrm{mm} \mathrm{Hg})$ & $115 / 78$ & $121 / 82$ \\
\hline Bust (cm) & 95 & 97 \\
\hline Shoulder circumference (cm) & 29 & 30 \\
\hline Thigh girth $(\mathrm{cm})$ & 53 & 60 \\
\hline $\begin{array}{l}\text { Favourable zones of activity of biological rhythms «Omega- } \\
M »\end{array}$ & \multicolumn{2}{|c|}{$\begin{array}{c}6.00,10.00,12.00 ., 16.00,18-20.00 . \\
\text { chronotype - arrhythmic }\end{array}$} \\
\hline $\begin{array}{l}\text { Number of steps per day (number) watch ONETRAK, mobile } \\
\text { application «Health» }\end{array}$ & 12134 & 9503 \\
\hline Distance covered on a treadmill $(\mathrm{km})$, excluding time & 2.4 & 4.5 \\
\hline Biological age (years), «Omega-M» & 18.3 & 23.7 \\
\hline $\begin{array}{l}\text { Adequacy of regulation processes (conv. units), «Omega- } \\
M » \text { (norm } 15-50 \text { conv. units) }\end{array}$ & 40.7 & 37.0 \\
\hline Athletic form (\%), maximum 100\%, «Omega» & 66 & 58 \\
\hline $\begin{array}{l}\text { The level of regulation of the cardiovascular system (conv. } \\
\text { units); } 81-90 \text { - medium; } 91-100 \text { - below average; } 101 \text { and } \\
\text { higher - low regulation value }\end{array}$ & 96.4 & 94.8 \\
\hline
\end{tabular}

A personal card of the morphofunctional state, which was compiled for each student N2, was of fundamental importance in improving knowledge about one's health. The card characterized the dynamics of individual indicators. This is of key importance in the informational components of the educational process in physical education. As an example, a health card of one of the students (young men) is shown (Table 2). At the same time, it should be noted a significant increase in the body weight of the subject, the deterioration of his sports form, and, as a consequence, an increase in biological age, in comparison with the passport. The subject 
also had an increase in fat mass from $19.1 \%$ to $22.4 \%$, sports form according to the «Omega-M» method worsened from $66 \%$ to $58 \%$. Of course, this student was consulted on the negative dynamics of results, it was recommended to reduce body weight, examples of mobile nutrition applications, online diet calculators were given. On the one hand, the young man's distance increased from $2.4 \mathrm{~km}$ to $4.5 \mathrm{~km}$ on a treadmill. On the other hand, physical activity decreased from 12,134 steps per day to 9,500 steps due to the lack of regular sports activities.

Thanks to the expansion of fitness means, the provision of an individual-typological card of health and the stimulation of physical activity, the study managed to achieve positive dynamics of the morphofunctional state of students $\mathrm{N} 2$.

\section{DISCUSSION}

The study by Shirokova (2020) presents the features of the application of the «soft» fitness methodology in regulating the quality of life of students of humanitarian specialties. The author has developed a method of «soft» fitness, which presupposes the use of mainly low-impact exercises of low and medium intensity. The technique also includes functional training, Pilates, stretching combined with relaxation exercises. In addition, individual homework assignments and recommendations for self-compilation and use of exercise complexes in the daily regimen were created. As a result of the experiment, the functional state of the respondents' cardiorespiratory system was normalized: the heart rate at rest decreased by $5.0 \%$, the blood circulation economization coefficient decreased by $6.4 \%$, Kerdo's vegetation index by $53.3 \%$ (a significant shift towards normotonia was noted). The results of functional tests with breath holding have significantly improved.

In the study by Goginava (2014), a methodology for physical education classes was proposed, including means of aerobic and anaerobic orientation, in the framework of the experiment, once a week, a swimming lesson and athletic gymnastics were conducted. At the end of the study, the author proved the developed methodology for heart rate at rest, Ruffier test, Skibinskaya index, assessment of somatic health according to Apanasenko's method, optimization of blood pressure and vegetative parameters, economization of myocardial activity.

The study by Stoycheva (2014) states the effectiveness of cardio training for female students in the form of aerobics and aerobics with a ball in the amount of $35-40 \%$ of the total volume of training hours, as well as functional training (Ftraininq, Best fit) for boys and girls in the amount of $55-60 \%$ of the total amount of study hours. In addition, the Tabata complex is popular, which allows to reduce the body fat content 9 times more than a traditional physical education program.

Innovative fitness technologies in the aquatic environment in the context of physical education are presented in the works of Nizhnik (2012) and Shutova \& Sharafieva (2019). This is how the possibility of using aqua aerobics as means of teaching swimming (at the initial stage) of girls in the framework of physical education is being studied, since: it develops the ability to control her body in the conditions of the aquatic environment, forms the «feeling of water»; increases physical fitness; forms water-support skills; improves the ability to perform exercises in horizontal and vertical body positions.

\section{CONCLUSIONS}

The results of the morphofunctional state of boys are higher than of girls. The results of the respondents at the beginning of each academic year are higher in comparison with the data at the end of the academic year. 
The standard deviation of the results is high at the beginning of the experiment, and slightly decreases towards the end. In group N2, practically in all the studied indicators, it was possible to achieve positive dynamics of results, within the framework of fitness classes and an increase in physical activity. At the same time, there was no significant improvement in the morphofunctional state in the groups. Significant differences were determined in $\mathrm{N} 2$ in the adequacy of the regulation processes, the integral indicator of the sports form, the level of physical activity (the number of steps per day). In N1, significant differences were determined in the level of physical activity and sports form only of girls. The research showed that lessons alone are not enough to improve the morphofunctional state of students.

In general, the morphofunctional state of students is within the normal range. For example, according to the index of stiffness of large vessels, body mass index, autonomic vascular tone, the level of blood oxygen saturation, the adequacy of regulation processes. At the same time, low values of the vital capacity of the lungs, low efficiency of the heart muscle during physical activity and the level of regulation of the cardiovascular system cause concern. The indicator of athletic form has not high values, especially at the beginning of the study in the group of girls. Peripheral vascular resistance, as an indicator of hemodynamics, exceeds the normal values, especially among girls, which may further contribute to the occurrence of hypertension. At the end of the experiment, in N1 and N2, it was not managed to reach the physiological norm of steps per day. Therefore, it is necessary to individually control the morphofunctional state, to select adequate means of physical education, based on fitness, and to find approaches to increasing the physical activity of students.

\section{REFERENCES}

Andryushchenko, L.B., Bodrov, I.M., Zaytsev, V.A., Buyanova, T.V. \& Nosov, S.M. (2018). Esteck complex application for age-specific functionality tests. Teoriya i Praktika Fizicheskoy Kultury, (9), 16-18 [in Russia].

Antonova, I.N., Shutova T.N., Nosova, A.V. \& Efremova N.G. (2019). The initial level of physical fitness and the reaction of the heart muscle to physical activity of first-year students. Uchenye zapiski universiteta imeni P.F. Lesgafta, 11(177), 21-25 [in Russia].

Antonova, I.N., Shutova, T.N. \& Nosova, A.V. (2019). Efficiency of scheduled physical education classes at the University of Economics. Uchenye zapiski universiteta imeni P.F. Lesgafta, 4(170), 14-18 [in Russia].

Bochkareva, S.I., Buyanova, T.V., Vysotskaya, T.P., Golubnichiy, S.P. \& Averyasov, V.V. (2018). Online education resources applied in academic physical education process. Teoriya i Praktika Fizicheskoy Kultury, (3), 44-46.

Chew, L., Tavitian-Exley, I., Lim, N. \& Ong, A. (2021). Can a multi-level intervention approach, combining behavioural disciplines, novel technology and incentives increase physical activity at populationlevel? BMC Public Health, 21(1), 120. https://doi.org/10.1186/s12889-020-10092-x

Edholm, P., Veen, J., Kadi, F. \& Nilsson, A. (2021). Muscle mass and aerobic capacity in older women: Impact of regular exercise at middle age. Experimental Gerontology, 147, 111259. https://doi.org/10.1016/j.exger.2021.111259

Finkelstein, E.A., Haaland, B.A., Bilger, M., Sahasranaman, A. \& Sloan, R.A. (2016). Nang EEK, «Effectiveness of activity trackers with and without incentives to increase physical activity (TRIPPA): a randomised controlled trial". The Lancet Diabetes \& Endocrinology, 4(12), 983-995. https://doi.org/10.1016/S2213-8587(16)30284-4 
Fühner, T., Kliegl, R., Arntz, F., Kriemler, S. \& Granacher, U. (2021). An Update on Secular Trends in Physical Fitness of Children and Adolescents from 1972 to 2015: A Systematic Review. Sports Medicine, 51(2), 303-320. https://doi.org/10.1007/s40279-020-01373-x

García-Hermoso, A., Ramírez-Vélez, R., Alfonso-Rosa, R.M. \& del Pozo Cruz, B. (2021). Cardiorespiratory fitness, physical activity, sedentary behavior, and circulating white blood cells in US youth. Scandinavian Journal of Medicine and Science in Sports, 31(2), 439-445. https://doi.org/10.1111/sms.13845

Gowin, M., Cheney, M., Gwin, S. \& Wann, T. (2015). Health and fitness app use in college students: A qualitative study. American Journal of Health Education, 46(4), 223-230. https://doi.org/10.1080/19325037.2015.1044140

Hou, Y. \& Liu, S. (2021). Research on green physical education teaching method from the perspective of ecological civilization. Fresenius Environmental Bulletin, 29(11), 9821-9829.

Junger, J., Junger, A. \& Ostrowski, P. (2020). Body composition of trainees undergoing EMS training with respect to their nutrition. Journal of Physical Education and Sport, 20(1), 12, 97-101. https://doi.org/10.7752/jpes.2020.01012

Jakicic, J.M., Davis, K.K., Rogers, R.J., King, W.C., Marcus, M.D., Helsel, D., Rickman, A.D., Wahed, A.S. \& Belle, S.N. (2016). Effect of wearable technology combined with a lifestyle intervention on longterm weight loss: the IDEA randomized clinical trial. JAMA, 316(11), 1161-1171. https://doi.org/10.1001/jama.2016.12858

José Enrique, M.-G., Arroyo-Del Bosque, R. \& Jiménez-Eguizábal, A. (2021). Level of physical condition and practice of physical activity in adolescent school children. Apunts. Educacion Fisica y Deportes, 143, 1-8. https://doi.org/10.5672/apunts.2014-0983.es.(2021/1).143.01

Joensuu, L., Kujala, U.M., Kankaanpää, A., Syväoja, H.J., Kulmala, J., Hakonen, H., Oksanen, H., Kallio, J. \& Tammelin, T.H. (2021). Physical fitness development in relation to changes in body composition and physical activity in adolescence. Scandinavian Journal of Medicine and Science in Sports, 31(2), 456-464. https://doi.org/10.1111/sms.13847

Katewongsa, P., Pongpradit, K. \& Widyastari, D.A. (2021). Physical activity level of Thai children and youth: Evidence from Thailand's 2018 report card on physical activity for children and youth. Journal of Exercise Science and Fitness, 19(2), 71-74. https://doi.org/10.1016/j.jesf.2020.11.002

Klochkov, S.O., Klyuchnikov, M.S., Sinitsina, Yu.Yu., Vychik, A.A., Samoilov, A.S., Sereda, A.P., Chadina, A.V. \& Medvedev, S.V. (2016). Integrated assessment of the health status of highly qualified athletes using the Estek System Complex medical software and hardware. Moscow: Federal Medical and Biological Agency of Russia [in Russia].

Kurmaeva, E.V. (2013). Fitness programs as a means of forming physical culture of students ' personality. Physical education of students, 1, 37-39 [in Russia].

Loginova, S. E. (2014). The combination of means of aerobic and anaerobic orientation in physical education classes at the university. Doctor Thesis. Tambov.

Makeeva V.S., Shirokova E.A. \& Shchegoleva M.A. (2019). About the possibility of using fitness technologies in the program to ensure the subjective well-being of university students. The world of science, culture, and education, 1(74), 318-321 [in Russia].

Melero-Cañas, D., Morales-Baños, V., Manzano-Sánchez, D., Navarro-Ardoy, D. \& Valero-Valenzuela, A. (2021). Effects of an Educational Hybrid Physical Education Program on Physical Fitness, Body Composition and Sedentary and Physical Activity Times in Adolescents: The Seneb's Enigma. Frontiers in Psychology, 11,629335. https://doi.org/10.3389/fpsyg.2020.629335

Nizhnik, G. N. (2012). Swimming training for girls aged 18-20 using water aerobics. Doctor Thesis. Moscow. 
Osipov, A.Yu., Kudryavtsev, M.D., Kopylov, Yu.A., Kuzmin, V.A., Panov, E.V. \& Kramida, I.E. (2018). The possibility of a significant increase in the level of motor activity in students with the use of the potential of computer technology. Physical education of students, 22(5), 265-271. https://doi.org/10.15561/20755279.2018.0506

ONETRAK user statistics (2020). Retrieved from: https://onetrak.ru/usermap/

Pogodina, S.V., Liskonog, L.V. \& Bridko, V.V. (2014). The physical condition of students depends on the level of fitness. Physical culture, Sport-Science and Practice, (4), 9-13 [in Russia].

Research and production company Dynamic Technologies (2019). The system of complex computer research of physical condition of athletes "Omega-sport", the user manual. Retrieved from: http://www.dyn.ru

Saykina, E.G. \& Ponomarev, G.N. (2012). Fitness technologies: concept, development and specific features. Fundamental Research, 11(4), 890-894 [in Russia].

Shi, B. (2021). Wearable exercise monitoring equipment for physical exercise teaching process based on wireless sensor. Microprocessors and Microsystems, 81, 103791. https://doi.org/10.1016/..micpro.2020.103791

Shutova, T., Vysotskaya, T., Bochkareva, S. \& Bodrov, I. (2020). Physical education of students with poor health. Journal of Human Sport and Exercise, 15(Proc2), 177-188. https://doi.org/10.14198/ihse.2020.15.Proc2.08

Shutova, T.N., Kondrakov, G.B., Averyasova, Y.O. \& Filimonova, Y.B. (2018). Student health management model: Group / individualized training modules. Teoriya i Praktika Fizicheskoy Kultury, (9), 30-32 [in Russia].

Shutova, T.N. (2017). Fitness technology models for academic physical education improvement using esteck system complex. Teoriya i Praktika Fizicheskoy Kultury, (9), 30-32 [in Russia].

Shutova T.N. \& Andryushchenko L.B. (2017). Young people's motor activity encouraging fitness technologies based on global approach. Teoriya i Praktika Fizicheskoy Kultury, 2017-January(3), 5456 [in Russia].

Shutova, T. N. \& Sharafieva A. V. (2019). Aquafitness. Moscow: Plekhanov Russian University of Economics.

Shirokova, E. A. (2020). Features of the application of the method of "soft" fitness in the regulation of the quality of life of students of humanities. Doctor Thesis. Moscow.

Shirokova, E.A. \& Makeeva, V.S. (2019). The impact of low-intensity work mode using complex Body and Mind technologies on the physical well-being of students. Uchenye zapiski universiteta imeni P.F. Lesgafta, 10 (176), 377-381 [in Russia].

Stepanov, M.Yu. (2009). Express assessment of the functional state of athletes. Tchaikovsky: Tchaikovsky State Institute of Physical Culture [in Russia].

Stoicheva, S. S. (2014). Functional training of students on BEST FIT in a pedagogical university as a tool for improving the functional capacity of the body. Achievements of university Science, 9, 61-65 [in Russia].

Zakariya, N.Z.E. \& Rosli, M.M. (2021). Physical activity prediction using fitness data: Challenges and issues. Bulletin of Electrical Engineering and Informatics, 10(1), 419-426. https://doi.org/10.11591/eei.v10i1.2474

Zhong, F. (2021). Experiment of biological pulse sensor and its application in physical education. Microprocessors and Microsystems, 81, 103781. https://doi.org/10.1016/j.micpro.2020.103781

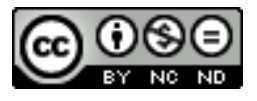

This work is licensed under a Attribution-NonCommercial-NoDerivatives 4.0 International (CC BY-NC-ND 4.0). 